\title{
Behandeling van kinderen met Dravetsyndroom met nervus vagus stimulatie
}

De diagnose Dravetsyndroom wordt doorgaans gesteld op de kinderleeftijd. Het is een moeilijk behandelbare epilepsie. Om de aanvallen te doen afnemen worden naast een combinatie van anti-epileptica alternatieve therapieën aangeboden, zoals nervus vagus stimulatie. In deze bijdrage worden twee cases gepresenteerd die naast de voordelen van deze behandeling ook de keerzijde laten zien.

In Nederland is bij ongeveer 200 personen de diagnose Dravetsyndroom (DS) gesteld. Het gaat om kinderen en volwassenen met therapieresistente epilepsie, debuterend in het eerste levensjaar, bij wie aanvullende behandelmethoden als ketogeen dieet en nervus vagusstimulatie (NVS) al op jonge leeftijd overwogen kunnen worden. De effectiviteit van NVS bij kinderen met de diagnose DS is slechts uit retrospectief onderzoek bekend. Uit een Amerikaanse enquête blijkt dat hoewel NVS bij ruim een kwart van de kinderen leidde tot een aanvalsreductie van $\geq 50 \%$ en bij ruim de helft van de kinderen de aanvallen minder talrijk werden, $25 \%$ van de ouders voor hun kind met de diagnose DS niet opnieuw voor deze behandeling zou kiezen. Voordat wordt besloten tot NVS bij deze kinderen dienen, veel meer nog dan bij anti-epileptica, met de ouders de voor- en nadelen te worden besproken.

\section{Ziektegeschiedenissen}

De jongen $\mathrm{H}$. was acht jaar oud toen hij een NVS model I03 kreeg. De diagnose DS werd gesteld op basis van een duplicatie in het SCNiA-gen. Voorafgaand aan de implantatie was met een combinatie van topiramaat, levetiracetam, stiripentol en clobazam (na valproaat en ketogeen dieet) bereikt dat hij ongeveer vijf tot acht tonisch clonische aanvallen per maand had met daarnaast verschillende keren per maand een focale aanval met verminderde gewaarwording die vaak gecoupeerd moest worden. Omdat hij in slaap series stille convulsies had, werd hij bewaakt met een pulsoxymeter. Daarnaast had hij de hele dag atypische absences en myoclone hoofdknikken, soms tien tot vijftien in een uur. Als bijwerkingen van stimulatie traden heesheid en hoesten op. Door de instellingen aan te passen werd het kuchen iets minder, maar de heesheid bleef en het aantal aanvallen nam dramatisch toe.
Het aantal convulsies bleef met de maand toenemen. Kaliumbromide bracht de in clusters voorkomende tonischclonische aanvallen terug van inmiddels honderd naar één tot twee per maand. Herstarten van valproaat deed de absences en schokjes verdwijnen, maar het effect op de convulsies hield geen stand, waarop de kaliumbromide werd vervangen door fenfluramine. Daarmee kreeg H. een betere aanvalscontrole die nog steeds stand houdt. De NVS was al uitgezet voordat $\mathrm{H}$. startte met fenfluramine, mede op zijn eigen uitdrukkelijke verzoek. In de jaren dat de NVS aanstond, had H. er last van: zodra de NVS aanging begon zijn stem te trillen en werd iel. Konden ze het overdoen, dan hadden $\mathrm{H}$. en zijn ouders de NVS niet laten plaatsen. Niet alleen omdat het effect uitbleef, maar ook omdat de operatie erg tegenviel wat betreft napijn en het effect op zijn stem $\mathrm{H}$. veel last gaf. $\mathrm{H}$. (nu I6 jaar oud) en zijn ouders overwegen de NVS en de electroden te laten verwijderen, maar zien op tegen een nieuwe operatie.

Bij het meisje J. werd in dezelfde periode als bij H. een NVS geplaatst. Zij moest toen nog vijf jaar worden en kreeg de diagnose DS op basis van een nonsense mutatie in het SCNIA-gen. Haar tonisch-clonische of met een dwangstand van hoofd en ogen inzettende hemiclonische aanvallen varieerden in frequentie van één tot drie per week en hielden ondanks noodmedicatie geregeld tien minuten aan. Een paar keer per jaar had ze een status epilepticus met ziekenhuisopname. Tevens had ze iedere ochtend schokjes met het hoofd naar opzij waarbij ze knipperde met de ogen en niet goed bereikbaar was. Met het avondeten herhaalde dit zich. Op school had ze veel absences. In slaap was bewaking nodig met een pulsoxymeter. Ze gebruikte valproaat, levetiracetam en stiripentol toen besloten werd om additioneel een NVS te plaatsen. J. was 
destijds een goede eter, voor wie een ketogeen dieet niet haalbaar was. Met topiramaat kreeg ze visuele hallucinaties met angst. Ook bonkte ze met haar hoofd tegen de muur. Een juiste instelling van de NVS (model ro3) heeft een klein jaar geduurd: tweemaal werd de stroomsterkte teveel verhoogd waardoor ze overprikkeld werd. Met NVS heeft J. nauwelijks nog convulsies gehad die langer dan tien minuten duurden. Het aantal grote aanvallen bleef echter gelijk. Clobazam bracht het aantal convulsies wél naar beneden, maar moest na een maand worden gestopt vanwege depressieve klachten als bijwerking. Ethosuximide gaf korte tijd minder schokjes en absences, maar maakte J. apathisch en moest worden gestaakt omdat ze weigerde het nog langer in te nemen. GWP42003-P (cannabidiol), dat werd gegeven in het kader van een onderzoek, had effect op oogknippers en schokjes, niet op de convulsies en moest worden gestaakt vanwege voedselweigering en extreme vermoeidheid. Na vier jaar werd de NVS vervangen door een Io6SR-model, dat naast reguliere stimulatie ook stimuleert als met een aanval de hartslag versnelt. Door vervolgens deze functie nog iets gevoeliger in te stellen, duurden convulsies nog slechts één tot vier minuten. Sindsdien is nog maar zelden noodmedicatie nodig. Er is overwogen of J. met fenfluramine kon worden behandeld: vanwege lichte hartklepregurgitatie bleek dit helaas niet mogelijk. Op I2-jarige leeftijd ontwikkelde J. onlangs clusters convulsieve aanvallen, wat het nodig maakte deze te doorbreken met clonazepam.

\section{De effectiviteit van NVS}

In gecontroleerde onderzoeken is het effect van stimulatie met therapeutische parameters vergeleken met het effect van subtherapeutische parameters (George et al., I995; Handforth et al., I998). Deze onderzoeken, die voornamelijk uitgevoerd werden bij volwassenen, hebben geleid tot registratie van NVS voor focale epilepsie. Behandeling gedurende drie maanden met therapeutische parameters resulteerde in de ene studie in een aanvalsreductie van $\geq 50 \%$ bij $31 \%$ van de patiënten en in de andere studie bij $23 \%$. Met subtherapeutische parameters was dit respectievelijk $13 \%$ en $16 \%$, wat een statistisch significant verschil is. In de enige gecontroleerde studie bij kinderen met een focale of gegeneraliseerde epilepsie was na 20 weken behandeling het verschil tussen high- en low-output (therapeutisch versus subtherapeutisch), respectievelijk I $6 \%$ en $21 \%$ aanvalsreductie $\geq 50 \%$ niet significant (Klinkenberg et al., 2012). Wat bekend is over het effect van NVS bij kinderen en volwassenen met de diagnose DS, is door Dibué-Adjei et al. (2017) gebundeld in een metaanalyse van retrospectieve gegevens over 68 patiënten, afkomstig uit 13 onderzoeken, verschenen in peer-reviewed tijdschriften. Met NVS behaalt 55,2\% een aanvalsreductie van $\geq 50 \%$. De leeftijd van de patiënten staat niet vermeld.
De behandelduur was in de meeste onderzoeken één tot twee jaar.

Het effect van NVS neemt toe met de duur van de behandeling: op basis van hun studie bij 56 kinderen met overwegend focale epilepsie rapporteerden Serdaroglu et al. (20II) dat na zes maanden behandeling 9,8\% van de kinderen een aanvalsreductie van $\geq 50 \%$ had bereikt, na twee jaar $24 \%$, na drie jaar $46,4 \%$ en na vijf jaar $54 \%$. NVSmodellen die extra stimulatie geven op het moment dat een ictale tachycardie optreedt (Io6SR, SenTiva), lijken een grotere aanvalsreductie te geven dan modellen die deze functie niet hebben (zoals de I03) (Hamilton et al., 20I8). Er werd een enquête gehouden via de sociale media onder leden van de Amerikaanse ouderorganisatie van kinderen met de diagnose DS, die hun kind hadden laten behandelen met NVS (Ali et al., 2017). Het betrof 49 patienten die als kind een NVS hadden gekregen. NVS gaf bij $28,5 \%$ een aanvalsreductie van $\geq 50 \%$. Van de ouders vond $55,8 \%$ dat NVS had geholpen het aantal aanvallen terug te brengen, $83,7 \%$ vond dat de ernst van de aanvallen was afgenomen. In deze publicatie valt op dat slechts $16,3 \%$ van de ouders tevreden was over de NVS. Toch gaf $59, \mathrm{I} \%$ van de ouders aan opnieuw te kiezen voor behandeling met NVS. Een kwart van de ouders zou niet opnieuw kiezen voor NVS.

\section{Tot slot}

Samenvattend blijkt uit retrospectief onderzoek dat NVS bij ruim de helft van de kinderen met de diagnose DS een aanvalsreductie $\geq 50 \%$ geeft, maar dat $25 \%$ van de ouders op basis van de ervaringen met de NVS van hun kind een volgende keer niet opnieuw voor implantatie zou kiezen. Als een anti-epilepticum niet aanslaat kan dit worden gestaakt zonder verdere consequenties. Met NVS heeft het kind een implantaat, dat, hoewel het chirurgisch kan worden verwijderd, in de meeste gevallen blijft zitten. Het is belangrijk om ouders eerlijk en goed te informeren over de huidige onderzoeksgegevens, hun voornamelijk retrospectieve karakter en de ervaringen van ouders van kinderen met de diagnose DS, zodat ouders samen met hun behandelaar in dialoog een weloverwogen keuze kunnen maken voor hun kind.

De behoefte aan prospectieve data is groot. De Nederlandse epilepsiecentra participeren in een nieuw gestart register, waarin wereldwijd prospectief het effect van diverse NVSmodellen op de aanvalsfrequentie wordt vastgelegd. In een subgroep-analyse van het DS zal duidelijk worden wat NVS voor kinderen met dit syndroom kan betekenen. Het register zal hiermee in de toekomst een beter inzicht geven in het effect van de diverse NVS-modellen op de aanvalsfrequentie. 


\section{Referenties}

Ali R, Elsayed M, Kaur M et al. Use of social media to assess the effectiveness of vagal nerve stimulation in Dravet syndrome: A caregiver's perspective. Journal of the Neurological Sciences 2017;375:146-149.

Dibué-Adjeia M, Fischer I, Steiger HJ et al. Efficacy of adjunctive vagus nerve stimulation in patients with Dravet syndrome: A meta-analysis of 68 patients. Seizure 2017;50:147-152.

George R, Sonnen A, Upton A et al. The vagus nerve stimulation study group. A randomized controlled trial of chronic vagus nerve stimulation for treatment of medically intractable seizures. Neurology 1995;45:224-230.

Hamilton P, Soryal I, Dhahri P et al. Clinical outcomes of
VNS therapy with AspireSRI (including cardiac-based seizure detection) at a large complex epilepsy and surgery centre. Seizure 2018;58:120-126.

Handforth A, DeGiorgio CM, Schachter SC et al. Vagus nerve stimulation therapy for partial-onset seizures. A randomized active-control trial. Neurology 1998;51:48-55. Klinkenberg S, Aalbers MW, Vles JSH et al. Vagus nerve stimulation in children with intractable epilepsy: a $\mathrm{r}$ andomized controlled trial. Dev Med Child Neurol 2012;54:855-61.

Serdaroglu A, Arhan E, Kurt G et al. Long term effect of vagus nerve stimulation in pediatric intractable epilepsy: an extended follow-up. Childs Nerv Syst 2016;32:641-646.

\section{Hoe minder toezicht, hoe groter de kans op SUDEP}

SUDEP - Sudden unexpected death in epilepsy - is de meest voorkomende epilepsie-gerelateerde doodsoorzaak. Inmiddels zijn er verschillende risicofactoren voor het optreden van SUDEP vastgesteld, waarvan het hebben van (nachtelijke) tonisch-clonische aanvallen de grootste risicofactor is. In het onderzoek dat hier wordt beschreven stond de vraag centraal of het intensiveren van nachtelijk toezicht in woonzorginstellingen het SUDEP-risico verlaagt.

Er zijn aanwijzingen dat circadiaanse factoren van invloed zijn op SUDEP: (I) SUDEP is meestal slaap-gerelateerd, (2) het risico op SUDEP is hoger wanneer iemand nachtelijke tonisch-clonische aanvallen heeft (Lamberts et al., 20I2). Verder lijkt toezicht ook een rol te spelen: SUDEP treedt vaker op als iemand alleen is (Lamberts et al., 2012, Langan et al., 2005). Een recente Cochrane-review geeft echter aan dat er very limited and low quality evidence is dat nachtelijk toezicht het risico op SUDEP zou kunnen verkleinen (Maquire et al., 2016). Dit is een dilemma voor woonzorginstellingen voor mensen met epilepsie en een verstande- lijke beperking. In deze populatie is de SUDEP-incidentie namelijk aanzienlijk (Klenerman et al., I993; McKee et al., 2000). Een recente audit bij de Stichting Epilepsie Instellingen Nederland (SEIN) toonde aan dat met het gebruik van een akoestisch waaksysteem zonder videomonitoring een derde van de nachtelijke aanvallen werd gemist (van der Lende et al., 20I6). In dit vervolgonderzoek werd nagegaan wat de SUDEP-incidentie is in woonzorginstellingen en wat het effect is van nachtelijk toezicht op het SUDEP-risico (van der Lende et al., 20I8).

\begin{tabular}{|c|l|}
\hline Graad I & Geen akoestisch waaksysteem EN slaapt alleen EN geen fysieke controles elke I5 minuten \\
\hline Graad 2 & $\begin{array}{l}\text { Akoestisch waaksysteem } \\
\text { Kamergenoot } \\
\text { Ten minste elke I5 minuten fysiek een controle }\end{array}$ \\
\hline Graad 3 & $\begin{array}{l}\text { Akoestisch waaksysteem EN kamergenoot } \\
\text { Akoestisch waaksysteem EN aanvullend systeem (matrassensor / videomonitoring) } \\
\text { Akoestisch waaksysteem EN fysiek een controle elke I5 minuten }\end{array}$ \\
\hline
\end{tabular}

Tabel 1 Gradering van nachtelijk toezicht 